\title{
Technology-based adaptation of think-pair-share utilizing Google drive
}

\author{
Norah C. Slone ${ }^{1}$ and Nathanel G. Mitchell ${ }^{2}$ \\ Keywords: Think-Pair-Share; learner-centered; Google drive; technology; teaching
}

Framework

The Think-Pair-Share activity (TPS; Lyman, 1981, 1987) is a learner-centered and highly effective collaborative teaching strategy that is widely used in higher education. The TPS activity promotes student learning through a sequence of three "phases." First, students individually reflect on subject matter, then pair with a partner in class to discuss the information, and finally share ideas from their discussions with the class as a whole. TPS is believed to not only enhance student learning but it also engages all students in discussions, including those who may be more reserved and less likely to share unprompted in class (Karge, Phillips, Jessee, \& McCabe, 2011). Instructors may be able to assess how students are understanding the material by walking around to listen in on various group reflections before then facilitating a larger class discussion.

The use of simple online tools, such as Google Drive (i.e., "Google docs"), may provide a platform that facilitates the adaptation of TPS activities. Utilizing Google Docs to facilitate a TPS activity encourages students to take an active role towards investigating a teacher-prompted question in one area, collaborating with peers to add to an electronic document based on the instructor question, and finally projecting their findings on the screen to the larger group. Studies to this point have only evaluated the utility and satisfaction of Google Docs to facilitate small group (i.e., approximately 3 students on average) collaborative weekly reflections and other essay-type writing assignments outside of the classroom (e.g., Denton, 2012; Zhou, Simpson, \& Domizi, 2012). However, research has yet to make the pedagogical connection linking Google Docs with TPS nor has the effectiveness for enhancing student learning through in-class collaborative activities been evaluated.

Google Drive is a free and easy-to-use technology on which small groups of students can record their findings simultaneously from their laptops or other tablet devices. The compilation of findings recorded on the Google Doc can be viewed on a projector screen while students present their information to the class as a whole. Although the in-class use offers a collaborative activity to promote in-depth learning of new material, one additional benefit of Google Drive is that the information recorded may be continually accessed once the class session is completed.

\section{Making it Work}

The Google Docs TPS activity was recently utilized in a graduate-level abnormal psychology class in which students were expected to learn how to competently render diagnoses in clinical practice. Accurately diagnosing clients is a complex skill requiring critical thinking and careful application of knowledge from course materials. A TPS activity was used to facilitate deeper

\footnotetext{
${ }^{1}$ Instructor, School of Professional Psychology, Spalding University, nslone@spalding.edu

${ }^{2}$ Assistant Professor and Chair of the Health Psychology Emphasis Area, School of Professional Psychology, Spalding

University, nmitchell01@spalding.edu
} 
levels of understanding and application of course content. For example, the Google Docs TPS activity allowed students to record information about particular diagnoses (e.g., distinguishing features, etiology, risk and protective factors, cultural considerations, treatment implications) in small groups.

Before class, students were asked to bring computers, tablets, or other electronic devices by which they could access the Internet. Upon arriving to class, students were asked to volunteer to receive an emailed link to a Google document (outline previously prepared by instructor) that was then projected onto a screen. Students were able to quickly access the document from their email. The link can also be sent via email prior to the class beginning, to ensure all students have access to the document.

Students with computers/tablets were asked to serve as the "recorders" for a small group of 1-4 students. In small groups, students were instructed to reflect on and work and together to fill in the prompts displayed on the Google Doc. Students not only saw their findings as they were all typing into the same Google Doc, but could view information other students were recording simultaneously as well.

The instructors assessed the groups' understanding of the content as recorded on the Google Doc by walking to each group to provide individualized feedback based on questions and needs, and monitored student engagement and contribution as they typed their ideas, and to ensure that groups were on-task throughout the class session. Once the groups were finished compiling information into the Google Doc, each group demonstrated understanding by sharing their findings with the class. As findings were discussed and debated, students could continue to make notes and update information in the Google Doc throughout the discussion. After the content of the Google Doc was discussed and evaluated in class, students were then provided access to the information after class for future reference. Given that students had access to the mutually developed Google Doc after class for their studies, it may be important for instructors to review work completed to ensure valid and correct information was recorded. One way the final Google Doc was reviewed and disseminated by the Instructor was through downloading the completed Google Doc to a Word document, saving the reviewed copy, and posting it in a Word document to an online learning platform for the course. Not only could students in the course easily access the document, but they would have the information in an easily printable format. If no online learning platform is used in the course, the document can also be emailed to the class or readily accessed from the Google Doc link itself; however, instructors and students need to be aware that Google Docs automatically saves all updates and previous information recorded is not stored.

As with the traditional TPS activity, the Google Doc TPS adaptation may be helpful for instructors from a wide variety of disciplines wanting to provide an opportunity for students to gain a deeper understanding of course material, offer an opportunity for students to reflect individually and in pairs, and then share information on their findings with the class as a whole through the Google Doc. It may also provide a basis for continuous learning given accessibility after the class session.

Very little preparation is needed by the instructor to implement the Google Docs TPS activity. The primary preparation is to decide upon the content about which instructors would like students to reflect and discuss. Once content is determined, creating a chart, table, or other prompt/guide to which students can respond is often very helpful. Instructors will need to create this document on the Google Drive before class. Google Drive automatically saves the information each time the document is updated, ensuring the most updated copy is available and 
readily accessible for the class session. If students and instructors are interested in old versions or wording, it may be helpful to record this information elsewhere before closing the Google Doc, as only the final draft will be saved.

\section{Future Making it Work and Student Feedback}

Qualitative data were recently gathered concerning the Google Doc TPS activity with doctoral students in clinical psychology $(N=25)$. The data were gathered immediately after the implementation of the exercise at approximately 10 weeks into the course. Students were asked to what extent the Google Doc TPS activity contributed to their learning of course content for which the activity was designed.

Overwhelmingly, students indicated that they benefited from discussing course content, and the Google Drive technology provides a flexible and useful guide to support learning. Further, many commented on learning beyond the content from the required readings through reflections and discussions of responses on the Google Doc.

As the use of web-based technology such as the Google Drive become ubiquitous in our student's lives, it may be necessary to adapt empirically-supported teaching interventions, such as the TPS, to be more culturally relevant and collaborative. The landscape of higher education continues to change rapidly, and instructors must be willing to find creative ways to adapt effective face-to-face activities through integrating technology. Our experiences indicate that the use of Google Drive may be an important tool for supplementing traditional instruction.

\section{References}

Denton, D. W. (2012). Enhancing instruction through constructivism cooperative learning, and cloud computing. TechTrends, 56, 34-41. doi: 10.1007/s11528-012-0585-1

Karge, B. D., Phillips, K. M., Jessee, T., McCabe, M. (2011). Effective strategies for engaging adult learners. Journal of College Teaching \& Learning, 8, 53-56. Retrieved from http://journals.cluteonline.com/index.php/TLC/index

Lyman, F. (1981). The responsive classroom discussion. In Anderson, A. S. (Ed.), Mainstreaming digest. College Park, MD: University of Maryland College of Education.

Lyman, F. (1987). Think-Pair-Share: An expanding teaching technique: MAA-CIE. Cooperative News, 1, 1-2.

Zhou, W., Simpson, E., \& Domizi, D. P. (2012). Google docs in an out-of-class collaborative writing activity. International Journal of Teaching Learning in Higher Education, 24, 359-375. Retrieved from http://www.isetl.org/ijtlhe/ 